\title{
Violencia y programación infantil en la televisión salvadoreña
}

\author{
Camila Calles Minero \\ camila.calles@utec.edu.sv \\ Dirección de Investigaciones Universidad Tecnológica de El Salvador
}

\section{Resumen}

Este trabajo evidencia la violencia que se transmite en las franjas infantiles de la televisión salvadoreña y canales infantiles de cable. Para ello se utilizó el método cuantitativo-cualitativo en la observación de 112 franjas televisivas que contienen 593 programas infantiles, en los cuales se encontró que las niñas, niños y adolescentes en El Salvador están expuestos a claras acciones de violencia física, verbal y psicológica. En el $78 \%$ de los programas que se analizaron existen una 0 más acciones de violencia. Solo el $2 \%$ de la programación infantil es producida en el país, el resto es creada en el extranjero con realidades nada cercana a la salvadoreña, puesto que la mayor parte de los protagonistas de los programas son blancos y masculinos; el país tiene población mestiza, y la mayoría es del sexo femenino. La programación infantil difunde estereotipos como el hombre fuerte y la mujer débil; la belleza centrada en la figura delgada y la tez clara; y la disputa de grupos como inteligentes contra tontos, bellos contra feos.

Palabras clave: Medios de comunicación, programación infantil, violencia en televisión, violencia infantil, programas de televisión para niños, investigación científica.

\begin{abstract}
This study demonstrates the violence that is broadcast in El Salvador's child prime time channels and also in child cable programming. The method used on this research was a quantitative-qualitative one. A total of 112 TV bands were watched and analyzed. These contained a total of 593 television programs for children. It was found out during the analysis that the Salvadorian girls, children, and adolescents are totally exposed to physical, verbal, and psychological violence. In $78 \%$ of the programs, there is one or more violence display. Only $2 \%$ of children's programming is made in the country; the others are made abroad with realities that don't have anything to do with the Salvadorian real life. Most of the main characters are Anglo-Saxon and male; however, El Salvador has a mixed race population, being female the majority of it. Children's programming broadcast stereotypes like the strong man vs. the weak woman. The beauty is focused on a slim shape and a fair skin complexion. Finally, there is also groups' dispute in the content of each of the programs, for example: fool ones vs. smart ones, good looking ones vs. ugly ones, and stronger vs. weaker.
\end{abstract}

Keywords: Media, children's programming, violence on television, childhood violence, television programs for children, scientific research. 


\section{Introducción}

La televisión, un invento de inicios del siglo pasado, permite a varias generaciones vivir sus fantasías por medio de una pantalla, en donde se presenta un mundo ideal y en ocasiones hasta trágico; un mundo de ficción con elementos sociales y cotidianos, que son muy reales y cercanos a la población. Bajo esa premisa, y contemplando que la violencia en El Salvador es parte de la dinámica social diaria, para esta investigación se planteó como objetivo general evidenciar la violencia que se transmite en las franjas infantiles de la televisión salvadoreña y canales infantiles de cable. Para lo cual se establecieron como objetivos específicos el identificar las formas de violencia y las diferencias entre la señal abierta y la señal cerrada de televisión.

Según el avance de la vigésima tercera edición del diccionario de la Real Academia de la Lengua Española, televisión es un sistema de transmisión de imágenes a distancia a través de ondas electromagnéticas. Pero en ese traslado de ondas no solo tienen que ver elementos de la electrónica, física y otras ciencias exactas, más bien están decoradas y arregladas con elementos culturales y cotidianos, en la recepción interviene en gran medida el contexto social de quienes transmiten los mensajes y de quienes los reciben.

Un grupo importante, en cuanto a número y sensibilidad, de receptores de esos mensajes de la "caja mágica" son los niños y las niñas que se sientan frente a ella y que asumen lo que ven como su mundo más próximo y real. El tema de la violencia en la televisión está en la palestra mundial desde hace varias décadas, al punto de plantearla como enemiga de las familias y como lo más nocivo de los medios de comunicación.

Tur y Grande (2009) establecen que la violencia ingresó a la programación infantil desde los años 70, cuando aparecen las creaciones japonesas para la televisión. La programación infantil se nutre en un $70 \%$ del género de dibujos animados, y la industria nipona era la mayor suministradora en ese momento, según Matilla (2005; citado por Tur y Grande, 2009). Por su parte, Gutiérrez (2011) asegura que los programas con contenidos violentos se han incrementado en las últimas dos décadas en El Salvador. Esto se evidencia en la pro- gramación televisiva que actualmente está al acceso de los menores de edad.

Los mensajes televisivos tienen su propio lenguaje y características específicas para llegar a cada persona que los ve. Ese lenguaje es el que utiliza la imagen en movimiento para establecer una conexión entre el receptor y el emisor. SpieIberg (1993) aseguró que las escenas violentas en el cine o la televisión estimulan mucho más a los espectadores a imitar lo que ven que las escenas reales que aparecen en los noticieros. Para este cineasta estadounidense, "en las películas, la violencia se filma con una iluminación perfecta, un escenario espectacular y a cámara lenta, lo que la convierte incluso en algo romántico".

La televisión es, tal vez, uno de los medios de comunicación de masas más analizados. Varias investigaciones se han centrado en su influencia, sus contenidos, su naturaleza técnica, su incidencia en los comportamientos de la población. Las posturas al respecto son opuestas. Hay quienes aseguran que los actos de violencia por parte de los menores de edad son impulsados por las escenas que ven en la pantalla; otros aseguran que los menores de edad que se sientan frente a la "caja mágica" no son autómatas, y los actos de violencia tienen que ver más con la problemática estructural que la sociedad enfrenta.

Levine (1997) apunta que el debate sobre los efectos perjudiciales de la televisión en los niños y niñas ha terminado. Plantea que no hay que teorizar tanto al respecto, pues los más de cuarenta años de investigación demuestran que "la exposición repetida a niveles altos de violencia en los medios de comunicación les enseña a algunos niños y adolescentes a resolver los conflictos interpersonales con violencia, "y que a muchos otros" a ser indiferentes a esa solución" (Levine, 1997).

Diversos autores apuntan a que la televisión influye en las acciones, los valores y las creencias de sus espectadores, pero no de la misma manera sobre todas las cosas. Depende de cuánto tiempo se pase frente a la pantalla y del contenido de los programas que se vean. El conocimiento del espectador y su ambiente social, en particular del contexto social o familiar, es factor determinante para paliar el influjo de la "pantalla chica". "Gracias a la televisión, un niño es- 
tadounidense presencia un promedio de 8 mil homicidios y 100 mil actos de violencia antes de haber terminado la escuela primaria" (Popper y Condry 1998, pág. 96).

La televisión puede verse como un servicio de telecomunicaciones, es decir, diversas posibilidades de comunicación sometidas a diversas exigencias técnicas, dotadas unas de mayor autonomía gramatical, sintáctica y expresiva; mientras que otras están más ligadas a exigencias inmediatas de comunicación para usos de consumo. (Eco, 1984).

En El Salvador se cuenta no solo con señal abierta, se tiene también opción del sistema de cable. Carranza, Rosales y Carbajal (2000) establecen que la televisión por cable tiene ventajas sobre la televisión libre. Una de ellas es que puede entregar muchos más canales; además, es de costo relativamente bajo; el campo receptor es delimitado y depende de qué tan sofisticado sea el aparato receptor, se puede establecer interactividad ente emisor y receptor.

Hay que tomar en cuenta que en El Salvador existen normativas que pretenden regular los contenidos televisivos. La principal es la Constitución de la República; existe además el Reglamento para Teatros, Cines, Radioteatros, Circos y demás Espectáculos Públicos de la Dgepryt (2011) y con el que controlan los contenidos que ve la infancia salvadoreña y el público en general, que data de 1948, y su última reforma se realizó en 1976.

Otras leyes de la República que tienen disposiciones para controlar los contenidos televisivos son: la Ley de Protección Integral de la Niñez y Adolescencia y la Ley por una Vida Libre de Violencia para las Mujeres en El Salvador. La programación televisiva y cinematográfica también está controlada por el Decreto legislativo $\mathrm{N}^{\circ} 647$, y a escala internacional existen convenios y declaraciones en las que se establece el respeto a los derechos de la infancia, la adolescencia y la mujer, tales como la Declaratoria Universal de Derechos Humanos, los pactos internacionales de derechos humanos y el Protocolo Facultativo del Pacto Internacional de Derechos Civiles y Políticos, la Declaración de los Derechos del Niño, la Declaración Americana de Derechos y Deberes del Hombre y la Convención interamericana para prevenir sancionar y erradicar la violencia contra la mujer, o denominada Convención de Belém do Pará (ONU, 1994).
Para esta investigación se tomó la violencia como la expresión abierta de comportamientos que implican forzar o hacerse daño físicamente a otra persona (o a uno mismo, como en el caso del suicidio), y por tanto incluye cualquier acción, en contra del deseo de uno, que cause heridas, la muerte (asesinatos), o la amenaza de herir, golpear o asesinar (Gerbner y Gross, 1976).

Además, la OMS (2002) la define como el uso deliberado de la fuerza física o el poder, ya sea en grado de amenaza o efectivo, contra uno mismo, otra persona o un grupo o comunidad, que cause o tenga muchas probabilidades de causar lesiones, muerte, daños psicológicos, trastornos del desarrollo o privaciones. Existen tres tipos básicos de violencia: física, verbal y psicológica. Dentro de esas expresiones de violencia, se tiene que retomar la que se ejerce contra la mujer.

\section{Metodología}

Se analizaron ocho canales de televisión cerrada o por cable exclusivamente dirigidos a la infancia y ocho canales de la televisión abierta, que son los únicos que contemplan en su programación franjas infantiles exclusivamente. En los canales salvadoreños se analizaron programas transmitidos durante el horario de las franjas infantiles; en el caso de los canales de cable se vio el prime time.

Se midió la frecuencia de variables como: golpes, empujones, gritos, humillaciones, malos tratos, estereotipos, entre otras. Se analizó cualitativamente con los resultados de dos grupos focales; uno con menores de edad y otro con padres y madres de familia. Los programas televisivos se sometieron a una observación estructurada y se grabaron para guardarlos como evidencia y análisis. Se tomó una muestra semanal para cada canal.

Se consideraron a los personajes, la presencia de estereotipos culturales y las escenas en cuanto a la temática que trataron. Para el procesamiento de los datos, se utilizó el programa de análisis estadístico SPSS.

Para la observación estructurada, las entrevistas y los grupos focales se construyeron guías de observación, validadas por expertos. 


\section{Resultados}

De las 112 franjas infantiles analizadas, 56 son de la señal abierta y 56 de la señal cerrada; en total se registraron 593 programas. No todos los canales salvadoreños tienen programación infantil. El estudio logró identificar las formas de violencia, las cuales pertenecen a los tipos de violencia física, verbal y psicológica.

Se encontraron 2.914 acciones violentas físicas, verbales y psicológicas, además de daños al medio ambiente y presencia de armas. En el 78\% de los 593 programas de televisión vistos, hay al menos una acción de violencia. Solamente en 32 de las 112 franjas infantiles, es decir el 28\%, están limpias de violencia. La distribución de las acciones violentas en los programas fue de $67 \%$ de violencia física, $21 \%$ de violencia verbal y $12 \%$ de violencia psicológica.

En total se encontraron 1.921 muestras de violencia física, y la que mayor frecuencia presentó fue los golpes, de los que se observaron 431; la segunda con mayor frecuencia fueron escenas en donde se tiran objetos, de las que se contabilizaron 391; los empujones fue la tercera acción de violencia física más observada, 320. Cabe hacer notar que el estudio detectó la presencia de un homicidio en un programa de los 593 analizados.

En cuanto a la violencia verbal, la acción más presente son los gritos; y se da en contextos que varían desde peleas, hasta escenas de alegría y entusiasmo, en donde los personajes tienden a reaccionar con uno o varios gritos. La segunda acción en frecuencia son los insultos; se dan tanto contra otros personajes o hacia sí, además suelen presentarse no solo en contextos de peleas, amenazas o provocaciones, también aparecen en conversaciones entre personajes o escenas de convivencia cotidiana entre los diferentes personajes. Este tipo de violencia no siempre está acompañado de otro tipo de violencia como golpes o gritos. El tercer tipo de violencia verbal en frecuencia son las provocaciones; estas se presentan cuando un personaje insta a una pelea, o es el primer paso para una escena en la que se observan también golpes y gritos; las provocaciones suelen estar acompañadas de algún tipo de violencia psicológica, como la humillación y el daño la autoestima.
Para el caso de la violencia psicológica, se observaron humillaciones, chantajes y daños a la autoestima. De estas, la mayor en frecuencia son los daños a la autoestima y se da en contextos sutiles y de cotidianidades de los personajes; aparecen acompañadas de risas de público, o celebraciones por parte de otros personajes. Algunos personajes suelen mostrar a otros como inútiles, poco inteligentes, simulan ser animales en su comportamiento; y esto es elogiado por otros, sirve de burla y en varias ocasiones quien recibe el daño a la autoestima no reacciona negativamente a ello, por el contrario, también se ríe de la situación. La segunda acción en frecuencia son las humillaciones que están muy asociadas con los daños a la autoestima; y la tercera en frecuencia son los chantajes, que se observaron incluso en escenas de ambientes escolares ejercidas por los profesores a los estudiantes.

De total de programas analizados, el 6,7\% registra al menos una escena en la que se ve algún tipo de daño contra el medio ambiente. Las acciones de violencia contra el medio ambiente muestran a personaje talando y destruyendo árboles; tirando basura al piso y al mar; maltratando a los animales, este maltrato ronda en negar la comida y golpear mascotas; haciendo explosiones que destruyen bosques y montañas, estas explosiones se dan en contextos de luchas y batallas con la utilización de armas.

Como resultado de los grupos focales, se tiene que los menores de edad reconocen con mayor facilidad la violencia física. Al dárseles una explicación del significado de violencia, los más grandes (10 años en adelante) reconocen la violencia psicológica y verbal; al dárseles la clasificación los tipos de violencia, todos identifican las acciones de violencia.

El estudio, además, caracterizó a los protagonistas en cuanto a su sexo, grupo étnico, si provoca conflictos o los resuelve. Hay que aclarar que no existe igual número de protagonistas que de programas, pues existen casos en donde hay más de un protagonista. En total se registraron 614. Además, hay que tomar en cuenta que los personajes se repiten; eso significa que un personaje fue contado en varias ocasiones. Del total de protagonistas de los programas infantiles que se transmiten en El Salvador, 64\% (380) son masculinos y $36 \%$ (213) la o las personajes son de sexo femenino. El predomi- 
no de los hombres como principales está acompañado, en muy pocas ocasiones, por los personajes secundarios femeninos; en cambio, los programas infantiles en donde son de sexo femenino las protagonistas, en la mayor parte de las ocasiones aparecen personajes secundarios de sexo masculino. Según la observación, existen 30 de las 112 franjas infantiles analizadas que contienen hasta cuatro protagonistas masculinos; las franjas que tienen igual cantidad de protagonistas femeninas, son nueve.

En cuanto a los grupos étnicos de los protagonistas, el estudio arrojó que en el $80 \%$ de las 112 franjas infantiles observadas hay uno o más personajes de la etnia blanca; en el $68 \%$ hay uno o más personajes no humanos (animales, robots, alienígenas, etc.); en el $25 \%$ hay uno o más personajes de la etnia latina; en el $15 \%$ hay uno o más personajes afrodescendientes; en el $10 \%$ de las franjas hay personajes de otras etnias (china, japonesa, india); no apareció la etnia indígena en alguna de las franjas de programación infantil. Dentro de esta clasificación se colocó como grupo étnico a los personajes no humanos para poder clasificarlos.

La observación de las franjas infantiles contempló, además, establecer si los protagonistas provocaban conflictos y además, si resolvía conflictos. El 52\% de los protagonistas resuelve conflictos. El $29 \%$ provoca conflictos en el desarrollo de la trama del programa; y el 19\% protagonistas ni resuelven ni genera conflictos. La generación de conflictos se da en cuanto a que los personajes son los que inician disputas con otros personajes, establecidas por luchas de grupos y defensa de intereses. La mayor parte de los protagonistas son los encargados de resolver los conflictos provocados por los antagonistas; los personajes principales tienen a comportarse como líderes y voz de mando ante la resolución de los conflictos que se desarrollan en la trama de los programas.

Otro de los elementos observados en el análisis de las franjas infantiles fue la presencia de estereotipos dentro de las tramas. Se buscó la presencia del estereotipo hombre fuerte mujer débil, es decir, de mostrar a los personajes masculinos como fuertes, inquebrantables, no perdedores, y a los personajes femeninos como delicados y fácilmente doblegables, cuidadosos.
Otros estereotipos que se buscaron fue el de belleza, colocando a los personajes principales con características de tez clara, cabello rubio y liso, de complexión delgada; la disputa de grupos, que se refiere a la presentación dentro de las tramas de los programas infantiles de grupos opuestos que luchan entre ellos, inteligentes contra tontos, bellos contra feos, fuertes contra débiles, entro otros.

El análisis estableció que el 61,30\% del total de los programas tiene al menos un tipo de estereotipo; de ese porcentaje, el $21,20 \%$ corresponde al estereotipo de disputa de grupos; el 20,70\% corresponde al estereotipo de hombre fuerte/mujer débil, y el 19,40\% al estereotipo de belleza.

El estudio, además, Identificó la diferencia entre la señal abierta y la señal cerrada de televisión en la cantidad de escenas de violencia que se transmiten en ellas. En total se vieron 16 canales de televisión, ocho de la señal abierta nacional (solamente esa cantidad de canales en esa señal transmite programación infantil), y ocho de la señal cerrada, número de canales de la señal cerrada que son exclusivamente infantiles y para adolescentes. De las 112 franjas analizadas, 56 corresponde a la señal abierta y 56 a la cerrada. De las 112 franjas analizadas, 45 se concentran solamente en horario de la tarde y 45 solamente en la jornada de la mañana, y 22 en ambas.

Los análisis estadísticos se realizaron aplicando las pruebas no paramétricas $U$ de Mann-Whitney y Kruskal-Wallis para comparar las dimensiones relacionadas con la cantidad de programas y las señales por las cuales se transmiten las franjas infantiles de televisión. Se encontró mayor cantidad de programas en la señal cerrada.

En cuanto a la violencia física, se determinó que existe mayor frecuencia de golpes, heridas, peleas, empujones, objetos tirados, objetos arrebatados en la señal de cable. Al contrastar las acciones de la violencia física con los días en los que se transmiten las franjas de televisión en donde aparece (día de semana o fin de semana), se registraron 80 franjas de programación infantil durante los días de semana; y para los fines de semana, 32. El análisis estadístico arrojó que golpes, objetos tirados, heridas, peleas, empujones, objetos arrebatados aparecen con mayor frecuencia durante las franjas de los fines de semana. 
En cuanto a las franjas en las que se transmiten, el estudio no establece diferencia del número de golpes, heridas $y$ acciones de tirar objetos que se ven tanto por la mañana como por la tarde. En cambio, sí registra mayor cantidad de objetos que se arrebatan y el número de empujones tanto por la mañana como por la tarde.

En relación con la violencia verbal, se encontró igual cantidad de insultos en las señales abierta y por cable. La presencia de los gritos, provocaciones y amenazas es mayor en la señal por cable. A excepción de los gritos, las demás formas de violencia verbal aparecen con igual frecuencia los días de semana y los fines de semana. Los gritos se ven más durante los fines de semana. El análisis establece que no hay diferencias en la cantidad de este tipo de violencia por la mañana y por la tarde.

Para el caso de la violencia psicológica, el estudio establece que se transmiten más humillaciones, acciones con daños a la autoestima y acciones que contiene chantajes en la señal cerrada. Las humillaciones se ven más durante los fines de semana y los daños a la autoestima y chantajes se ven igual cantidad en ambas jornadas. Se observan más humillaciones y daños a la autoestima durante la jornada de la tarde, en cambio, hay igual cantidad de chantajes mañana y tarde.

Se analizó la presencia de armas en los programas infantiles de televisión, y se encontró que, del total de las franjas de televisión observadas, en el 51,40\% de ellas se presentan armas de algún tipo. Se registraron más armas en la televisión por cable; se ven con igual frecuencia tanto los días de semana como los fines de semana, y ya sea por la mañana o por la tarde.

Otro de los temas estudiados fue la presencia de acciones contra el medio ambiente que aparecen en las franjas de programación infantil. Estas aparecen con igual frecuencia en las dos señales de televisión, y ya sea por la mañana o por la tarde. Los días en donde se registran más acciones en contra del medio ambiente son los de fin de semana.

En cuanto a los estereotipos buscados, se encontró que el hombre fuerte/mujer débil, la belleza, entendida como alguien rubio, delgado y tez clara, así como la disputa de grupos, aparecen más en la señal por cable. En relación con los días en que aparecen los estereotipos, solo hay diferencia en la disputa de grupos que se observan más durante los fines de semana; los de más estereotipos aparecen por igual durante los siete días de la semana.

El estudio establece además que existe mayor cantidad de protagonistas que generan conflictos en la señal cerrada. Este tipo de protagonistas aparece en igual cantidad los días de semana y los fines de semana. Se ven con mayor frecuencia durante la jornada de la tarde.

Por su parte, los protagonistas que resuelven los conflictos aparecen con mayor frecuencia en la señal cerrada o por cable; los días de semana son en los cuales se observó mayor cantidad de protagonistas que resuelven conflictos, y durante las jornadas de la tarde.

Los grupos focales arrojaron elementos como el que los padres de familia, en un primer momento, no asumen su condición de reguladores de la televisión que ven sus hijos. Para aquellos el principal responsable es el Estado. Sin embargo, al conocer formas de ayudar a controlar la violencia, asumen la posibilidad de inculcar en sus hijos e hijas valores que les ayuden a enfrentar y procesar los elementos que visualizan frente al televisor.

Las niñas, niños y adolescentes están claros de que existe violencia en las franjas infantiles que ven desde sus casas; están conscientes de que es incorrecto golpear a las personas y burlarse de ellas; pero les causa gracia y se ríen de situaciones que incluyen acciones de violencia.

\section{Conclusiones}

En las franjas de televisión con programación infantil que se pueden ver en El Salvador, ya sea por señal de cable o televisión abierta, contienen acciones de violencia (física, verbal o psicológica), armas (de fuego y blancas), daños al medio ambiente, estereotipos y protagonistas con predominio del grupo étnico blanco, además de ser personajes que generan conflicos; y la mayor parte de los protagonistas son masculinos.

En el 78\% hay una o más acciones de violencia. Estos programas no se muestran como únicos, eso quiere decir que 
el mismo programa se repite en varias ocasiones dentro de la misma franja. Al comparar la señal cerrada con la abierta, esta última tiene menor cantidad de programas; sin embargo muchos de ellos son repeticiones de tramas y del programa en sí, por lo que hay mayor cantidad de escenas que se pueden ver en la televisión cerrada. El cable es una opción para muchos salvadoreños, sobre todo en la capital, pese a que tiene un costo monetario. Según la Superintendencia General de Electricidad y Telecomunicaciones (Siget), para el 2006 (dato más reciente obtenido) existían 608.58 aparatos de televisión entre los hogares salvadoreños; y para el 2010 cuatro de cada diez habitantes del área metropolitana de San Salvador tendrían en sus televisores el servicio de cable, sobre todo en los municipios de Antiguo Cuscatlán, Nueva San Salvador, en el departamento de La Libertad; Soyapango, Ilopango, Ayutuxtepeque y San Salvador Siget, 2006)

Es importante ver el porcentaje de violencia verbal y psicológica. Esta última con menor frecuencia, pero que, a juicio de Gómez, Salazar y Ocampo (2005), es riesgosa, pues es muy difícil de detectar. Muchas de las expresiones de violencia física pueden producir, también, un daño psicológico. Los dos grupos étnicos que más se difunden a través de las franjas infantiles de televisión son los blancos y los no humanos. No hay registro de protagonistas indígenas y los latinos son muy pocos. Esto indica que las acciones que se transmiten a través de la televisión y que se pueden ver en El Salvador están alejadas de la realidad inmediata de la infancia del país.

En la programación infantil existe invisibilización de la mujer, en el sentido que más de la mitad de los protagonistas (64\%) son del sexo masculino, eso hace recrear un mundo en el que los que tienen el papel principal y características diferentes son los hombres. El no mostrar a la mujer como igual ante los hombres se refuerza ante la aparición del estereotipo de hombre fuerte/mujer débil en los programas infantiles y de los cuales se encontraron 123.

El 61\% de los programas presentan al menos un estereotipo, entre lo que se mencionan hombre fuerte/mujer débil, beIleza y disputa de grupos. El estereotipo que más presencia tiene es la disputa de grupos, por lo que se concluye que los infantes que ven esos programas se están formando la idea de que siempre habrán grupos contrarios entre ellos y, por ende, conflictos.
Del estudio se concluye que sí hay diferencias para algunos tipos de violencia en la cantidad de acciones que se transmiten a través de la señal abierta y la de cable. Esta última es en donde se registra mayor cantidad de los tres tipos de violencia analizados (física, verbal y psicológica), mayor presencia de armas y estereotipos culturales. Sin embargo, no hay diferencia en cuanto a los daños contra el medio ambiente.

Muchas de las acciones de violencia que se observaron en las franjas de programación infantil se combinan con humor o alta densidad emotiva, sobre todo en los programas para adolescentes, y con la violencia psicológica.

Estos resultados se suman a la percepción de que la mayoría de la población salvadoreña $(76,5 \%)$ considera que las noticias que se transmiten por televisión, prensa escrita y la radio, sobre la violencia delincuencial (lesionados, muertos, robos, extorciones, etc.), afectan su estado emocional y mental. En este mismo sentido, una mayoría calificada $(70,1 \%)$ de la muestra en estudio expresó que la televisión y los juegos de video promueven las conductas violentas en los salvadoreños (Gutiérrez, J.R., 2011).

La programación de señal abierta, a la que se tiene mayor acceso por su no pago, es mucho menos en relación con la por cable, en cuanto a cantidad y variedad de programas. Son pocos los programas que se producen en el país; los programas que se transmiten son hechos en el extranjero.

Por parte del Ministerio de Gobernación, desde la Dirección General de Espectáculos Públicos, Radio y Televisión, hace uso de un reglamento no acorde a la realidad actual, puesto que fue creado en la década de los 70, y desde entonces los cambios que ha recibido son mínimos. Haría falta nueva normativa para regular la programación televisiva que se transmite en el país a través de la señal abierta.

Existen pocos proyectos en el país que apunten a contribuir a crear una mejor cultura de consumo de televisión, al igual que a controlar el tipo de programas televisivos que se transmiten en el país, pese a que actualmente en El Salvador el $40 \%$ de sus habitantes son menores de 18 años, es decir 2.4 millones de salvadoreños son niñas, niños y adolescentes (Unicef, 2011). 
El ver constantemente acciones de violencia, tanto en la vida cotidiana como por la programación televisiva, la salud mental de la infancia salvadoreña se vulnera. En el artículo 25 , literal " $h$ ", de la Ley de Protección Integral de la Niñez y la Adolescencia (2011) se establece que se deben de desarrollar programas permanentes para la prevención, atención y tratamiento de la salud mental de la niñez y adolescencia.

Muy poco se invierte en la población menor de 18 años en el país. Según Unicef (2007), para el 2007 solamente $\$ 3.4$ de cada $\$ 100$ del PIB van para la niñez salvadoreña. El 17\% del Presupuesto General de la Nación va para la niñez. Unicef (2007) recalca que anualmente el Estado salvadoreño gasta \$317 por cada niña, niño y adolescente. En cuanto a los gobiernos locales, estos invierten $\$ 2.80$ anualmente por cada menor de 18 años.

Queda abierta la posibilidad de otro estudio que, basado en estos resultados, evalúe el comportamiento de los infantes, luego de ser expuestos a programas televisivos con muestras de violencia explícita como los analizados en esta investigación.

\section{Referencias}

Bockelmann, F. (1983) Formación y funciones sociales de la opinión pública. España: Editorial Gustavo Gill.

Carranza, E., Rosales, S. \& Carbajal B. (2000) La eficacia de la función protectora del Estado y la familia frente a la incidencia de los medios de comunicación social en la salud mental de los menores, Tesis Universidad de El Salvador.

Comisión coordinadora del sector justicia (2009) Dice la LEPINA... Ley de Protección Integral de la Niñez y la Adolescencia. El Salvador: UTE/UNICEF

Córdova, A., Hernández L., Herrera, A. \& Mena, R. (2005) La televisión en El Salvador (canales) y compañías de televisión por cable y televisión digital, El Salvador: UCA editores.

Diccionario Real Academia de la Lengua (2001). Vigésima segunda edición

Dirección de Espectáculos Públicos, Radio y Televisión (2010), Evaluación de contenidos audiovisuales, conferencia, Escuela de Comunicaciones Mónica Herrera.

Eco, U. (1984) Apocalípticos e integrados, España: Lumen. Séptima edición.
García-Calderón, E. (1991) Televisión. Fundamentos, dispositivos, TV monocroma. Volumen I. España: Departamento de publicaciones de la E.T.S. Ingenieros de Telecomunicaciones.

Gerbner, G. \& Gross, L. (1976). Living with television: The violence profile. En: Journal of Communication, 26, p.173-199.

Gomez, E., Salazar, R. \& Ocampo, L. (2005) Gobernabilidad en crisis: delito, conflicto y violencia en América Latina. Editorial Librosenred. Recuperado de http://books.google.com.sv/books?id $=$ lgJhFnnvGzYC\&printsec=frontcover\&hl=es\#v=onepage\&q\&f =false

Grande, J. (1999) La influencia de la televisión y criterios para analizar su impacto social, político y cultural. El Salvador: Imprenta Universitaria.

Gutiérrez, J.R. (2011). La violencia social delincuencial asociada a la salud mental. Universidad Tecnológica de El Salvador, San Salvador.

Gutiérrez, R. (2011) Conversación personal realizada con el subdirector de canal 10, efectuada el 19 de junio de 2001.

Hernández, R., Fernández, C. \& Baptista, P. (2006) Metodología de la investigación. Cuarta edición. Mc Graw Hill.

Hodge, B. \& Tripp, D. (1988) Los niños y la televisión. España: Editorial Planeta. http://web.ua.es/es/comunicacioneinfancia/ documentos/doc-grupo-invest/articulos/indicadores-de-calidad-en-los-contenidos-audiovisuales-en-televisi-n-dirigidos-ala-infancia.pdf

Laguna de Paz, J., (1994), Régimen Jurídico de la Televisión. Privada. España: Marcial, $1^{\text {a }}$ edición.

Levine, M. (1997) La violencia en los medios de comunicación. CoIombia: Editorial Norma.

McLuhan, M. (1969). El medio es el masaje. Buenos Aires: Paidós

Popper, K. \& Condry, J. (1998) La televisión es mala maestra. México: Fondo de Cultura Económica.

SIGET (2006) Avance estadístico anual, El Salvador: Superintendencia General de Electricidad y Telecomunicaciones.

Spielberg, S. (1993) Revista Veja número 64. Brasil.

Tur, V. (2003) Indicadores de calidad en los contenidos audiovisuales de televisión dirigidos a la infancia. Recuperado de http:// web.ua.es/es/comunicacioneinfancia/documentos/doc-grupo-invest/articulos/indicadores-de-calidad-en-los-contenidosaudiovisuales-en-televisi-n-dirigidos-a-la-infancia.pdf

Tur, V. \& Grande, I. (2009) Violencia y prosocialidad en los contenidos televisivos infantiles visionados por menores en Alicante. Revista Zer, Vol.14-Núm. 27, págs. 33-59.

UNICEF (2011) Estado mundial de la infancia 2011: La adolescencia, una época de oportunidades. Estados Unidos: UNICEF

UNICEF/FLACSO (2009) ¿Cuánto invierte El Salvador en su niñez y adolescencia? El Salvador: UNICEF 